\title{
UNA APROXIMACIÓN A LAS CARACTERÍSTICAS ACTUALES DE LA MANO DE OBRA AGRÍCOLA EN EL VALLE DE MEXICALI*
}

\author{
Por \\ José A. Moreno Mena**
}

\begin{abstract}
RESUMEN
Este trabajo aborda, de manera sintética, algunas características de la estructura agraria, así como de productores agrícolas del valle de Mexicali. Se presenta un acercamiento a las condiciones en que se desarrolla la mano de obra actual en el sector agrícola del municipio de Mexicali. Para ello se toma como base información primaria obtenida de dos encuestas realizadas durante el periodo 1991-1994; la primera producto de un muestreo no aleatorio por cuotas aplicada a 150 trabajadores agrícolas del algodón; y la segunda de carácter aleatoria aplicada en 499 viviendas de trabajadores agrícolas en el valle de Mexicali por el Instituto de investigaciones Sociales de la Universidad Autónoma de Baja California y el Programa Nacional de Solidaridad con Jornaleros Agrícolas.
\end{abstract}

\begin{abstract}
This article is a synthesis of some of the characteristics of the agricultural structure, as well as of growers in the Valle de Mexicali area. It takes a close look at the working conditions of the farm labor force in the Mexicali county. To do this, it uses firsthand information obtained from two surveys made during the period 1991-1994 the first, the product of a non randon sampling applied to 150 farm workers in the cotton crop; the second, a random sampling made up of 499 families of farm workers in the Valle de Mexicali area, and carried out by the Social Research Institute of the Autonomous University of Baja California, and the National Solidary Program of Agricultural Day-workers.
\end{abstract}

* Este artículo fue recibido en junio de 1996 para ser publicado en la revista Estudios Fronterizos.

** Investigador del Instituto de Investigaciones Sociales de la Universidad Autónoma de Baja California. 


\section{INTRODUCCIÓN}

En los campos agrícolas mexicanos todos los años trabajan más de cuatro millones de jornaleros agrícolas, ${ }^{1}$ algunos de los cuales abandonan sus tierras por temporadas para retornar en épocas de cosecha; otros recorren la república constantemente en búsqueda de un trabajo, que por lo regular, resulta inseguro y mal pagado. ${ }^{2}$

Los trabajadores cumplen un papel de suma importancia en la producción agrícola, pues cosechan los productos que van a ser exportados o aquellos que se consumirán en el país.

Sin embargo, a pesar de su importancia en el ámbito de la economía nacional, sus condiciones económicas y sociales son deprimentes: en el trabajo se ven obligados a soportar horarios extenuantes; a recibir salarios raquíticos que apenas les reditúa el mínimo para subsistir. Sobra decir que las prestaciones laborales son casi siempre nulas; también el acceso a la educación, recreación y cultura está vedado para ellos.

En algunas regiones agrícolas de México, la población migrante ha sido el factor principal que ha permitido la conformacion del mercado laboral. Precisamente ese es el caso del valle de Mexicali.

El presente trabajo tiene el propósito de establecer un acercamiento a las características de la mano de obra en el sector agrícola del valle de Mexicali. Para ello, en una primera parte, se describen algunas características de la estructura agraria actual y de los principales empleadores de mano de obra en el valle. En un segundo apartado se desarrolla, a manera de propuesta, una tipología de los jornaleros agrícolas en la actualidad y las principales características que guarda este sector, tanto en su perfil como en su situación laboral. Para este último aspecto, se toman como fuentes de información los datos recabados en dos estudios de carácter empírico que se realizaron entre 1991 y $1994 .^{3}$ Finalmente se vierten algunas consideraciones finales,

1 El Programa Nacional de Solidaridad con Jornaleros Agrícolas reconoce para 1995 a cuatro millones de trabajadores en el país (PRONSIAG y UNICER, 1995). Para efectos de este ensayo, se utilizan indistintamente como sinónimos trabajadores, asalariados, jornaleros y peones agrícolas, a pesar de que puedan tener sus particularidades cada uno de los conceptos.

A finales de la década de 1980 , se calculaba que $20 \%$ de la mano de obra agrícola tenía empleo mientras que el restante $80 \%$ trabajaba por temporadas o por jornada, según el yolumen de la demanda. (Vanackere, 1988:171).

3 En 1991 se encuestó a 150 jornaleros agrícolas migrantes del algodón, en este caso se utilizó un muestreo no aleatorio por cuotas. La aplicación se efectuó en el lugar de mayor concentración de estos trabajadores, el ejido Estación Coahuila o Kilómetro 57 ubicado en el valle de Mexicali. Posteriormente, entre diciembre de 1993 y enero de 1994, mediante un convenio entre el Instituto de Investigaciones Sociales de la UABC y el Programa Nacional de Solidaridad para Jornaleros Agricolas se aplicó un cuestionario en 499 viviendas de trabaja- 


\section{ESTRUCTURA AGRARIA EN EL VALLE DE MEXICALI}

El Distrito de Riego número 14 donde está contenido el valle de Mexicali (que incluye al valle de San Luis Río Colorado, Sonora), cuenta con una superficie de 328,000 hectáreas, con una superficie dominada con obras de 250,000 , ha de las cuales 207,505 ha son susceptibles de riego para uso agrícola. El $61 \%$ son tierras ejidales y el $39 \%$ pertenece a la propiedad privada (la pequeña propiedad y el régimen de colonias). La superficie media es de 15 hectáreas por productor. El tamaño medio de la tenencia ejidal es de 17.9 ha mientras que el de la propiedad privada corresponde a 10.7 ha (Conagua, 1993:4).

En el padrón de usuarios para 1993 se registraron 14,671 usuarios con derechos de riego, divididos éstos en 7,067 ejidatarios para una supeficie de 136,237 ha.; y 7,626 pequeños propietarios y colonos con una superficie de 70,763 ha (CONAGUA, 1993:4), ${ }^{4}$

La tenencia de la tierra se finca en derechos de riego, correspondiéndole 19.3 ha por productor ejidal y 9.2 para la propiedad privada (CONAGUA, 1993:7). Las tierras se encuentran regadas con las aguas del Río Colorado.

A partir de las modificaciones al artículo 27 constitucional efectuadas en 1991, se viene realizando la transferencia del distrito de riego a los usuarios, mediante la creación de unidades de producción denominados módulos que agrupan tanto a ejidatarios como a los propietarios privados. En el distrito se tienen contemplados 23 módulos, de los cuales 20 corresponden al valle de Mexicali y los restantes a San Luis Río Colorado, Sonora,

En el valle de Mexicali, el patrón de cultivos actualmente se encuentra diversificado, correspondiéndole a los cultivos básicos (trigo en particular),

dores agrícolas, en este caso el muestreo fue aleatorio, se entrevistó a 914 jornaleros agrícolas. Precisamente es de estas fuentes de donde se toman los datos para caracterizar a los jornaleros agrícolas locales del valle de Mexicali y a los jornaleros migrantes ocupados en las hortalizas.

Los datos de la encuesta a jomaleros agricolas del algodón sólo se utilizan para efectos de comparación y de ninguna manera son concluyentes, pero sí nos dan una aproximación a las características de esta categoría de trabajadores.

4 En 1993 la Comisión Nacional del Agua (Conagua) realizó un documento denominado "Proyecto de desarrollo parcelario y de redes pequeñas de riego del Distrito de Riego número 14 Río Colorado", en el cual se presenta un resumen del valle de Mexicali, precisamente de ȩse estudio se toman los datos referentes al padrón de usuarios.

El Río Colorado es un río internacional entre México y Estados Unidos, cuya cuenca tiene una superficie aproximada de 624 kilómetros cuadrados que se extienden por los estados de Colorado, Wyoming, Utah, Nevada, Arizona, Nuevo México y California en los Estados Unidos. Desemboca en el golfo de California, atravesando una pequeña porción de territorio mexicano por los estados de Sonora y Baja Cal ifornia. En la república mexicana, el río recorte 160 kilómetros. 
CUADRO 1. Jornales de los principales cultivos en el valle de Mexicali.

\begin{tabular}{lccc}
\hline $\begin{array}{l}\text { Cultivos } \\
\text { principales }\end{array}$ & \multicolumn{2}{c}{ Por hectárea } & \\
& $\begin{array}{c}\text { F.T. } \\
\text { calificada }\end{array}$ & $\begin{array}{c}\text { F.T. no } \\
\text { no calificada }\end{array}$ & $\begin{array}{c}\text { Total de F.T. } \\
\text { por hectárea }\end{array}$ \\
\hline $\begin{array}{c}\text { Básicos } \\
\text { Trigo }\end{array}$ & 1.4 & 7.0 & 8.4 \\
Forrajes & & & \\
$\quad$ Alfalfa & 3.0 & 6.0 & 9.0 \\
$\quad$ Rye Grass & 1.3 & 7.0 & 8.3 \\
$\begin{array}{c}\text { Fibras } \\
\text { Algodón }\end{array}$ & 2.2 & 37.0 & 39.2 \\
Hortalizas & & & \\
$\quad$ Cebollín & 1.0 & 53.0 & 54.0 \\
$\quad \begin{array}{l}\text { Espárago } \\
\text { Frutales }\end{array}$ & 2.2 & 150.0 & 152.2 \\
& 4.0 & 120.0 & 124.0 \\
\hline
\end{tabular}

FUENTE: SARH, Delegación, B.C., Mexicali, B.C.,1992.

F.T.: Fuerza de trabajo.

la preminencia por superficie sembrada; en orden de importancia le siguen los forrajes (rye grass, alfalfa, cebada, sorgo), algodón y los cultivos hortofrutícolas.

Sin embargo, y a pesar de lo anterior, son las hortalizas y el algodon los que requieren el mayor porcentaje de la mano de obra agrícola en la actualidad, los cultivos hortícolas llegan a utilizar hasta 150 jomales $^{7}$ por hectárea, mientras que los básicos como el trigo sólo 8.4 jornales (ver cuadro 1). En ese sentido, los empleadores de fuerza de trabajo más importantes se encuentran precisamente en los productores, empacadores y maquiladores de esos cultivos, que son los que ocupan nuestra atencion y a los cuales describiremos brevemente.

En términos generales, los productores algodoneros son ejidatarios o pequeños propietarios que casi siempre han dependido, fundamentalmente,

6 En el ciclo 1994-1995, en el distrito de riego se cosecharon 186,438 hectáreas, de las cuales $44 \%$ correspondió al trigo; $26 \%$ a forrajes; $19 \%$ al algodón; $8 \%$ a las hortalizas y $3 \%$ a otros cultivos (SAGAR, 1993).

7 Un jornal es equivalente a 8 horas de trabajo/hombre por día como promedio. 
de los créditos de la banca oficial. Los primeros con una infraestructura para la producción limitada, mientras los segundos con acceso a tecnologías modernas en determinadas coyunturas. Ambos se encuentran descapitalizados actualmente.

Este tipo de productores presentan promedios que van de 12.4 a 15.3 hectáreas de riego por usuario; pocos son los que logran rentar más tierras para este cultivo.

Por lo regular, los productores de algodón utilizan mano de obra asalariada, de preferencia migrante, y en contadas ocasiones trabajo familiar no remunerado. Un porcentaje importante de ellos alquilan o compran máquinas pizcadoras. En tiempos críticos, cuando se presentan bajas en los precios internacionales del algodon, plagas, etcétera, entonces se ven obligados a sembrar otros cultivos, rentar su tierra o bien, a no sembrar en esa temporada.

En cuanto al grupo de los productores de hortalizas, como bien lo ha venido documentando Stamatis (1992b:64), no constituyen una población homogénea, su diferenciación se presenta fundamentalmente por la disponibilidad de recursos y comportamiento productivo, principalmente por las características del mercado hacia el cual destinan su produccion.

De un estudio que realizó Stamatis (1992b) a 287 productores, se obtuvo que por tenencia de la tierra, los productores de hortalizas se dividían en ejidatarios $39.9 \%$, colonos $16.8 \%$, ejidatarios arrendatarios $15.0 \%$, colonos arrendatarios $24.5 \%$ y arrendatarios en general $3.7 \%$.

La misma autora encontró que el $56.7 \%$ del total de productores analizados cultivaban la tierra haciendo uso exclusivo de sus derechos ejidales y privados; mientras que un $39.5 \%$ tomaban tierras en arrendamiento, además de sus derechos de posesión o propiedad; y solamente $3.7 \%$ usufructuaba la tierra exclusivamente mediante arrendamiento. ${ }^{8}$

De los hallazgos interesantes que conviene destacar es el referente a que la gran mayoría de los productores de hortalizas que cultivan sus tierras en posesión o propiedad, destinan su producción al mercado nacional; mientras que por el contrario, la gran mayoría de los ejidatarios y colonos que toman las tierras en arrendamiento orientan su producción bacia el mercado externo.

Por el tipo de asociación a la que pertenecen y sus formas de organización, Stamatis (1992b) los clasifica de la siguiente manera: $56.1 \%$ de los

8 Estos datos se obtuvieron de tres encuestas efectuadas a los productores de hortalizas durante el periodo 1987-1989, por Martha Stamatis Maldonado, investigadora del IS - UABC, para el proyecto "Producción de hortalizas mexicanas para el mercado norteamericano" (1989). 
productores de hortalizas están considerados en la categoría de pequeños productores; $16.4 \%$ en medianos productores y $27.5 \%$ a grandes productores.

En cuanto a la superficie cultivada por productor de hortalizas, se tiene una media de 18.8 hectáreas por productor que hace uso exclusivo de sus derechos como colono o ejidatario; mientras que para los colonos y ejidatarios que hacen uso de sus derechos y además rentan más tierras, les corresponde un promedio de 124.2 hectáreas por productor y los arrendatarios en sentido estricto 19.7 hectáreas por productor.

Los dos grandes grupos de empleadores, algodoneros y hortaliceros, desarrollan su producción (con sus diferentes modalidades) bajo logicas empresariales. Los grandes productores de hortalizas, ligados fundamentalmente por contratos de producción al capital extranjero, cuentan con empresas empacadoras de hortalizas que procesan el producto y lo preparan para exportarlo hacia los Estados Unidos.

Para 1993, se estimaba que $30 \%$ de la superficie total del distrito estaba rentada a productores nacionales y extranjeros (ConAGUA, 1993). Para 1996, la Secretaría de Agricultura, Ganadería y Desarrollo Rural reconoce que esta tendencia ha crecido hasta llegar a constituir $60 \%$ de la tierra arrendada (SAGAR, 1993).

\section{MERCADOS DE TRABAJO AGRÍCOLAS EN EL VALLE DE MEXICALI}

El valle de Mexicali históricamente ha sido receptor de fuerza de trabajo migrante. Ésta ha sido la variable básica de la estructura del empleo agrícola local, ${ }^{9}$ Desde su génesis como zona agrícola, el mercado de trabajo local había sido incapaz de satisfacer las necesidades de fuerza de trabajo, por lo que se tuvo que recurrir a la contratación de jornaleros foráneos. ${ }^{10}$

Tradicionalmente, el cultivo que más empleo ha generado en el valle ha sido el algodón. Durante décadas, una cantidad importante de trabajadores. migratorios han hecho presencia en el levantamiento de estas cosechas.

9 Sobre el papel de la migración en la conformación de la estructura agraria del valle de Mexícali, consúltese la obra de María Eugenia Anguiano Téllez, Estructura agraria y migracion en el valle de Mexicali (1995).

10 Por mercado de trabajo, se entiende

a la orbita espacial donde se realiza la fuerza de trabajo... El epicentro para determinar el nivel del mercado es el lugar de residencia de los jornaleros. Los trabajadores migrantes estacionales se encuentran inmersos en un mercado de trabajo nacional, pero hay algunos que se realizan en el marco de un mercado regional (Astorga, 1985:41). 
En la actualidad, aun con los cambios tecnológicos y productivos que se han operado, y a pesar de la crisis internacional de los precios de la fibra, se sigue sembrando algodon, aunque en menor medida. ${ }^{11}$ La mano de obra migrante continúa llegando también en menor proporción. ${ }^{12}$ Los cultivos hortícolas comienzan a resultar un atractivo para la mano de obra foránea.

En el sector agricola del valle de Mexicali actualmente encontramos un mercado de trabajo segmentado, en donde se identifican, por sus caracteristicas particulares, dos categorias de trabajadores agrícolas, uno, compuesto por jornaleros migrantes que vienen por temporadas; $y$ otro, por jomaleros locales que residen en el valle, éstos a su vez presentan ciertas subdivisiones que conviene matizar para efecto de tener una mayor claridad. $^{13}$

\section{Trabajadores agrícolas migrantes}

En este grupo encontramos a los pizcadores de algodon, que van siguiendo las rutas de las pizcas en las regiones agricolas del noroeste, concluyendo precisamente en el valle de Mexicali. Estos trabajadores se han especializado en la pizca de la fibra. Las tareas que realizan fundamentalmente son manuales, sin mucha calificación. Son los jornaleros que regularmente levantan las cosechas cuando se siembra algodón en los valles de Mexicali, Baja California, y San Luis Río Colorado, Sonora.

No existe una cuantificacion precisa de este tipo de trabajadores, su número varía de acuerdo con las necesidades requeridas. En la década de 1980, los productores y organismos oficiales estimaban hasta siete mil peones del campo por temporada (Moreno, 1988). En la actualidad, con los vaivenes de la siembra de la fibra, difícilmente pudiera pensarse en un número mayor a los dos mil.

Al terminar las cosechas, continúan su ruta migratoria circular. Eventualmente, algunos jomaleros deciden quedarse a radicar en el valle de Mexicali, engrosando el mercado laboral local.

1 En el último ciclo agrícola se presentó una coyuntura que permitió la siembra de 35,000 ha en 1995, lo cual rompe con la racha que venía sufriendo la fibra, puesto que en los dos ciclos anteriores se había dejado de sembrar por problemas de plagas y precios del mercado. Precisamente por esa razón no se ven reflejados los trabajadores agrícolas del algodón en la encuesta del nS-UABC, porque el levantamiento coincidió con el ciclo en que la siembra de la fibra se había reducido sustancialmente. De ahí que se haya recurrido a otra fuente de información primaria para describir las características de estos jornaleros.

12 Anteriormente con el "boom" algodonero de los años cuarenta y cincuenta, la cantidad de jornaleros variaba entre 30,000 y 40,000 , ahora las cantidades disminuyeron significativamente, y se ubican de acuerdo con las hectáreas sembradas.

${ }^{13}$ Sobre cada grupo hablaremos más detalladamente en las próximas páginas, aquí únicamente presentamos una somera descripción. 
Entre los trabajadores migrantes, también encontramos a los jornaleros de las hortalizas. ${ }^{14}$ Éstos, en su gran mayoría, no provienen de las corrientes migratorias tradicionales del algodon, sino que están conformados por jomaleros que ya cuentan con cierta especialización en determinados cultivos hortícolas. Un porcentaje importante de estos jomaleros provienen de los estados de Oaxaca y Guerrero y algunos son de origen mixteco, aunque su número es relativamente pequeño. ${ }^{15}$

Los trabajadores migrantes de las hortalizas tienen la posibilidad de laborar hasta nueve meses al año en el valle de Mexicali.

\section{Jornaleros agrícolas residentes o locales}

En cuanto a los trabajadores residentes o locales, tomando como base la caracterización que hace Martha Stamatis (Stamatis, 1992a) y los datos recabados en la investigación de campo del Instituto de Investigaciones Sociales (IIS) de la Universidad Autónoma de Baja California y el Programa Nacional de Solidaridad con Jomaleros Agrícolas (PRONSJAG), podemos distinguir las siguientes grupos de asalariados:

Jornaleros agricolas nativos. Son trabajadores que ya han nacido en la localidad, hijos de ejidatarios, pequeños propietarios y colonos locales, asi como de inmigrantes.

El mayor porcentaje de ellos (casi $70 \%$ ) trabajan de tres a nueve meses al año, principalmente en las cosechas de los cultivos hortícolas; algunos realizan tareas de especialización en el proceso de producción, como el de supervisión y control (capataces), operacion de maquinaria y equipo, administracion y eventualmente trabajan en los empaques y enlatadoras horticolas. ${ }^{16}$

Jornaleros agricolas inmigrantes. Estos peones agrícolas, aunque ya viven de forma permanente en el valle de Mexicali, no nacieron en la entidad. Aligual que los anteriores, tienen ocupación de tres a nueve meses al año, principalmente en los cultivos hortícolas, con una elevada rotación en el trabajo. Desarrollan fundamentalmente actividades manuales de poca calificación (labores de cosecha y "deshaije") pero con cierta especialización por cultivos. Se puede decir que aunque ya tienen su residencia

\footnotetext{
${ }^{14}$ Los denominamos así, porque en su gran mayoría se dedican a recolectar cosechas de hortalizas, en la encuesta del ns-UABC, $94 \%$ laboraban precisamente en esos cultivos, el resto estaba repartido en cultivos como algodón, cereales, forrajes y oleaginosas.

is De los 914 trabajadores entrevistados, solamente $6 \%$ correspondio a jornaleros migrantes de diferentes estados y étnias.

16 En el estudio del IIS-PRONSIAG, $89 \%$ de los trabajadores locales se dedicaban al cultivo de las hortalizas; mientras $10 \%$ a cereales, forrajes y oleaginosas; solamente $1 \%$ correspondió al algodón.
} 
habitual en el valle de Mexicali, en ocasiones se trasladan a otras zonas agrícolas del propio estado a continuar las pizcas. ${ }^{17}$

Las estimaciones basadas en datos de los productores hortícolas y el censo de 1990, nos dan un número aproximado entre 18,000 a 21,000 jornaleros nativos e inmigrantes (INEGI, 1991) es decir, que forman el conjunto mayoritario de los trabajadores agrícolas en el valle.

\section{CARACTERÍSTICAS SOCIODEMOGRÁFICAS DE LOS JORNALEROS AGRÍCOLAS DEL VALLE DE MEXICALI}

\section{Estados de procedencia de los jornaleros agrícolas}

En tomo a los estados de procedencia de los trabajadores agrícolas migrantes que se dedicaban al levantamiento de las cosechas del algodon, en el estudio de 1991-1992 (Moreno, 1994) se encontró que los más significativos y por orden de importancia, eran Sinaloa, Nayarit, Sonora, Michoacán, Chihuahua y Jalisco, es decir, los estados del noroeste y occidente del país.

Otro dato interesante es el referido a que $70 \%$ de estos trabajadores realizo, cuando menos, una escala en algún estado del noroeste de la república mexicana durante su trayecto laboral. Las entidades que más se visitaron (por orden de importancia) fueron Sonora, Sinaloa y otras ciudades de Baja California. Lo anterior nos confirma la existencia de una ruta migratoria definida, la del noroeste. ${ }^{18}$

Por los datos recabados, se deduce que su origen es eminentemente rural; $85 \%$ se dedicaban a las actividades relacionadas con el sector agropecuario, ya sea como jomaleros o bien pequeños productores de las zonas temporaleras, el resto en la construcción, servicios y trabajo por su cuenta. $^{19}$

\footnotetext{
${ }^{17}$ Esto se presenta, sobre todo, en aquellos trabajadores que laboran para las empresas hortícolas que tienen relación con otros campos de cultivo en los valles de la Trinidad, Maneadero y San Quintín, en Baja California.

18 En su peregrinar los jornaleros van construyendo rutas de cultivos, en donde una de las más importantes, por la cantidad de trabajadores que se desplazan, es la del noroeste que incluye a los estados de Nayarit, Sinaloa, Sonora, Baja California e incluso a algunas localidades del estado de California, Estados Unidos. En esas regiones, durante af́os, ha sido cotidiana la presencia temporal de estos "golondrinas" del trabajo rural. Entre los trabajos que han documentado este fenómeno están la obra de Luisa Pare, El proletariado agricola en México y de Florencio Posadas, El proletariado agricola en el estado de Sinaloa.

19 Las razones por las que emigraron tienen que ver fundamentalmente con la cuestión económica, por ejemplo, un alto porcentaje, el $55 \%$, manifestó que venían siguiendo las pizcas, éstos podrían ser migrantes permanentes; un $16 \%$ argumentó que se había terminado el trabajo en su tierra; mientras que un $13 \%$ llegaron con la intención de obtener mayores
} 
En cuanto a los migrantes de las hortalizas, de acuerdo con el estudio desarrollado por el IIS-UABC y el PRONSJAG en 1993-1994, se encontró que casi la mitad (46\%) de los peones agrícolas encuestados provenían del estado de Oaxaca, le siguen por orden de importancia Guerrero y Veracruz; por otra parte, del total de migrantes encuestados, $48 \%$ hablaban alguna lengua indígena (nS-PRONSJAG, 1994).

\section{Relación de los jornaleros agrícolas con tierras de cultivo}

En cuanto a su condición con la tierra, tomando los datos de los estudios mencionados, se tiene que los jornaleros agricolas migrantes del algodón y los de las hortalizas, en un porcentaje importante tenían nexos con la tierra en sus lugares de origen, $19 \%$ en el caso de los primeros y $15 \%$ en los segundos. Es decir, que pueden ser minifundistas, comuneros, ejidatarios o pequeños propietarios pauperizados que se ven obligados a vender su mano de obra para complementar sus raquíticos ingresos.

Ellos aprovechan la no coincidencia del ciclo de las cosechas en el valle de Mexicali u otros lugares, con el levantamiento de la cosecha de la producción de su tierra, y entonces migran en forma temporal. ${ }^{20}$

Por su parte los trabajadores agrícolas locales o residentes encuestados en el estudio del iIs-PRONSJAG, $49.9 \%$ resultaron ser nativos de Baja California, mientras que $50.1 \%$ procedian de otras entidades del país, es decir, inmigrantes; de estos últimos, poco menos de la mitad correspondió a personas que tenían menos de un año de residencia, a los que podríamos ubicar como de reciente migración y el restante a personas que tenían más de un año radicando en la región.

Por los estados de procedencia, $24.2 \%$ del total de trabajadores locales inmigrantes le correspondio al estado de Guanajuato; mientras que a Michoacán $25.7 \%$; Zacatecas $12.6 \%$; Sinaloa $8.7 \%$ y finalmente $8.2 \%$ a Jalisco. $^{21}$

En cuanto a la tenencia de la tierra, los resultados sobre las encuestas a los jornaleros agrícolas locales nos indican que $98.3 \%$ carecían de tierras de cultivo; pudiéramos aventurar que son en sentido estricto, peones que

ingresos. Sólo un pequef́o porcentaje (7\%) manifestó que habían venido con la intención de migrar hacia Estados Unidos, a los cuales podríamos ubicar dentro de los migrantes internacionales potenciales.

${ }^{20}$ La crisis generalizada del campo en el país está expulsando a campesinos pauperizados çonvirtiéndolos en asalariados.

21 Tradicionalmente Baja California ha recibido inmigración de Sinaloa, Michoacán, Jalisco, Guanajuato y Zacatecas, esta población por lo regular se queda a radicar en forma definitiva en las ciudades de la entidad; también ha sido tradicional que las migraciones temporales provengan principalmente de los estados de Sinaloa, Sonora, Nayarit y Chihuahua. 
dependen únicamente de su fuerza de trabajo para subsistir; algunos son hijos o familiares de ejidatarios que ya no alcanzaron tierras durante los repartos; otros, provenientes del proceso de descampesinización en el propio valle y algunos más que emigraron en forma definitiva de diferentes estados del país. Solamente $1.7 \%$ contaban con algún terreno de cultivo, sin embargo, un porcentaje pequeño, que no llegaba a $3 \%$, pertenecía a grupos de solicitantes de tierras.

\section{Sexo, edad, nivel educativo y estado civil}

En estos aspectos, existen algunas diferencias entre las características sociodemográficas de los dos grupos de trabajadores que les dan cierto matiz y conviene destacarlos.

Del grupo de los jomaleros agricolas migrantes del algodón, los hallazgos nos han indicado que la gran mayoría de los encuestados son del sexo masculino, en este caso hombres solos; mientras que en los migrantes de las hortalizas, se observa una importante participacion femenina, $21.2 \%$ son mujeres (IIS-PRONSJAG, 1994).

En cuanto al grupo de los jornaleros locales, la tendencia de la insercion de la mano de obra femenina se manifiesta con mayor importancia. En la encuesta de referencia, se obtuvo una participación de las mujeres del $29.5 \%$ para el grupo de los trabajadores nativos y $28.2 \%$ para los inmigrantes (IIS-PRONSJAG, 1994).

El trabajo femenino es bastante cotizado en algunas actividades manuales que se realizan en el valle mexicalense, tales como el amarre y empaque de cebollín o la selección de melon. ${ }^{22}$

En el mismo tenor, debe destacarse la incorporación de niños al trabajo, en la encuesta se detecto $8.2 \%$ de trabajadores menores de 14 años y $10.2 \%$ entre los 15 y 17 años. $^{23}$

\footnotetext{
22 En los distritos de riego más desarrollados, desde hace varios años se ha venido observando una fuerte inserción de la mano de obra femenina en los cultivos para la exportación, esto ha dado pie para que algunos autores hablen de una reciente feminización del trabajo agrícola; sobre este tópico, consúltese a María da Gloria Marroni de Velázquez, "La feminización del trabajo agrícola" (1993:56-64).

${ }^{23}$ Los datos obtenidos en la encuesta no reflejan lo que se observa en los campos de cultivo ya que el empleo de nifios pensamos que debe ser mayor. En la aplicación de la encuesta se presentaron al gunos problemas para captar la información relativa a los menores que trabajan, debido a que los informantes (en este caso los padres de familia) no incluyeron a todos los hijos como jornaleros, porque consideraron que el trabajo de alguno de ellos es complementario al salario familiar. En una encuesta que aplicó la investigadora de la UNAM, Antonieta Barrón, en la mayoría de las regiones hortícolas del pais, incluyendo Baja California, encontró que $15 \%$ de la población ocupada eran niños de 14 años y menos, ( $\mathrm{La}$ Jomada, Suplemento del campo. 1 de septiembre de 1992). Por lo que nos induce a pensar que la población infantil que trabaja en el valle de Mexicali está subestimada.
} 
CUADRO 2. Características generales: promedios porcentuales comparativos de trabajadores agrícolas migrantes del algodón y locales de las hortalizas.

\begin{tabular}{|c|c|c|c|c|c|c|c|c|c|c|c|}
\hline \multirow{3}{*}{$\begin{array}{l}\text { CARACTERISTICAS } \\
\text { GENERALES } \\
\text { Categoría }\end{array}$} & \multirow[b]{3}{*}{11} & \multirow{2}{*}{\multicolumn{6}{|c|}{$\begin{array}{c}\text { Edad \% } \\
\text { Rangos en años }\end{array}$}} & \multicolumn{4}{|c|}{ Edo. civil \% } \\
\hline & & & & & & & & & & & \\
\hline & & $12-18$ & $19-25$ & $26-36$ & $37-47$ & $48-58$ & $59-82$ & N.S & familiar & familiar & (promd) \\
\hline $\begin{array}{l}\text { Trabajadores agrícolas } \\
\text { migrantes del algodón }\end{array}$ & 0.0 & 8.0 & 19.0 & 31.0 & 25.0 & 10.3 & 6.7 & 0.0 & 79.0 & 21.0 & 2.8 \\
\hline $\begin{array}{l}\text { Trabajadores agrícolas } \\
\text { locales hortícolas }\end{array}$ & 1.6 & 16.5 & 26.0 & 22.7 & 15.0 & 11.4 & 6.1 & 0.7 & 52.4 & 47.6 & 4,8 \\
\hline
\end{tabular}

FUENTE: José Moreno Mena (1992), “Conformación del mercado laboral rural en el valle de Mexicali y las condiciones laborales de los jomaleros agrícolas"; IIS-PRONSJAG, (1994), "Encuesta a trabajadores agrícolas en el valle de Mexicali". 
La tendencia de la incorporación, cada vez más frecuente, de la mano de obra remunerada femenina e infantil se viene observando desde hace varios años en los distritos de riego del noroeste de la república mexicana, donde los cultivos hortícolas adquieren gran importancia, por ejemplo, en el valle de Culiacán, Sinaloa, según datos del Programa Nacional de Solidaridad con Jornaleros Agrícolas (Sánchez, 1992:148) para el ciclo 89-90, del total de la mano de obra empleada, $26 \%$ fue de mujeres; mientras que $33.37 \%$ de la población incorporada al trabajo agrícola eran niños. Para el ciclo 1992, la proporción creció hasta 33\% de mujeres.

Similar situación se presentó en el valle de San Quintín, Baja California en la temporada 1991, donde más de la mitad de la mano de obra ocupada en las actividades agrícolas correspondió a las mujeres y del total de trabajadores se detectó un porcentaje de $6.5 \%$ de mano de obra infantil (Sánchez, 1992:148). La magnitud de la inserción de la mano de obra femenina e infantil se puede explicar por el aumento de las actividades hortícolas. Estos cultivos son intensivos en mano de obra y las formas de contratación son más flexibles, lo que hace posible el trabajo de todos los miembros de la familia. ${ }^{24}$

En los cultivos algodoneros, básicos y forrajeros del valle de Mexicali, la incorporación de mujeres y niños no se venía observando en forma importante. Por lo que se hablaba de trabajo agrícola eminentemente masculino. En el caso de los niños, algunos participan en el trabajo junto con los otros miembros de la familia, formando parte de una cadena donde se enlazan diversas fases de las cosechas hortícolas, en este caso, su trabajo es complementario; otros laboran en forma individual, como cualquier jornalero adulto,

También es frecuente observar en los campos de cultivo hortícolas del valle de Mexicali, a pequeños lactantes que son llevados porque sus madres no tienen quien cuide de ellos mientras trabajan. Las parcelas de pronto se ven convertidas en verdaderas "guarderías". Las estrategias de sobrevivencia de las familias, conjugan diversos factores económicos, sociales y culturales. El aporte económico de los niños es fundamental para la reproducción de la familia. Por ello, la incorporación de los infantes como asalariados, se presenta a corta edad, a veces, desde los 7 años.

\footnotetext{
${ }^{24}$ En algunas regiones agrícolas del país, la mano de obra del niño es sumamente codiciada en ciertas fases de cultivos como de la manzana, el tomate, el chile y la piña, se utilizan grandes cantidades de mano de obra infantil por la mayor rapidez y agilidad para realizar las tareas debido a su poco peso, y también para ahorrarse salarios puesto que a ellos les pagan menos que a los varones adultos, tal es el caso de Durango y Loma Bonita, Oaxaca, ver Aguirre y Beltrán y Carton, Jornaleros agricolas de Mexico (1990:91,124,126).
} 
En el valle de Mexicali, por los datos que se han obtenido, se puede inferir que la mano de obra local y la migrante de las hortalizas, es un poco más joven que la migrante del algodon. En el estudio del IIS-PRONSJAG, se observ6 que los jomaleros de la region registraron mayores porcentajes en el rango de los 19-25 años (26.0\%), y en los de 26-36 (22.7\%); mientras que los migrantes del algodón el mayor porcentaje se ubico en los rangos de $26-36$ años $(31 \%)$ y $36-47$ ( $25 \%)$.

En ambas categorías de trabajadores se presentó un pequeño pero significativo porcentaje de mayores de 59 años, que trabajaban en igualdad de circustancias que los demás trabajadores.

En el sector agrícola, no existen parámetros definidos para medir los rangos de la edad productiva de los jornaleros agrícolas, como se ha mencionado anteriormente, en los campos se pueden observar a niños de siete años y a personas de más de 50 años de edad laborando.

\section{Educación de los trabajadores agrícolas del valle de Mexicali}

En cuanto al aspecto educativo, por los datos de los diferentes estudios se puede deducir que el nivel de los jornaleros locales es superior, tanto al de los jomaleros agrícolas migrantes de las hortalizas como también a los trabajadores migrantes del algodón. En el caso de estos últímos, en el estudio de 1991-1992 sólo llegaron a contar con un promedio de 2.8 años de escolaridad.

En la encuesta de 1993-1994 para los jornaleros locales, un porcentaje alto, $40.1 \%$ sí contaban con primaria completa, mientras que $41.7 \%$ no había finalizado su instrucción elemental.

Es una realidad que el trabajo estacional no contribuye a que los jornaleros puedan concluir su instrucción básica. Los programas que establecen instituciones de educación no formal, se enfrentan al desinterés de los empresarios que no consideran que deban de colaborar en la educación de sus empleados. También, a esto se suma la apatía de los propios trabajadores.

Los peones del campo dejan la escuela desde temprana edad para incorporarse a las actividades laborales, provocando con ello grandes problemas a la matrícula de las escuelas de educación básica y condenando a una parte del futuro de México a seguir reproduciendo el analfabetismo.

En cuanto al analfabetismo, resulta también más alto en los trabajadores migrantes. ${ }^{25}$ En el caso de estos últimos, en los mencionados

${ }^{25}$ El grado general de escolaridad en el país es de 6.5 años, mientras que en Baja California llega a 7.7 para 1995, (revista Comunidad Educativa de Baja Califomia, 1996). 
estudios se encontró que $44 \%$ no sabían leer ni escribir, ${ }^{26}$ contra $18.2 \%$ de los trabajadores locales.

Estos datos nos rebelan un grave problema de analfabetismo, sobre todo si consideramos que en el estado de Baja California la media es de $4.2 \%$, según el Intituto Nacional para la Educación de los Adultos (INEA). 27

\section{Estado civil de los trabajadores agrícolas del valle de Mexicali}

En cuanto al estado civil, $79 \%$ de los jornaleros migrantes del algodón encuestados en 1991 resultaron ser solteros, con sus diferentes modalidades: solteros en sentido estricto, separados, viudos y divorciados; $21 \%$ sí estaban casados o tenían compromisos familiares. Por su parte, en lo que respecta a los jomaleros migrantes de las hortalizas, se manifiest $50 \%$ con compromisos familiares mientras que la otra mitad eran solteros.

Esta característica va a tener relación con su capacidad de ingreso y la variable migratoria, puesto que los trabajadores que siguen las pizcas difícilmente pueden establecer un hogar, se han convertido en verdaderos nómadas del mercado de trabajo nacional; además, en el valle de Mexicali no existe la infraestructura para albergar temporalmente a familias itinerantes.

Los trabajadores que arriban al valle mexicalense a las pizcas del algodon, difieren mucho del patrón migratorio de los jornaleros que llegan al valle de Culiacán, Sinaloa o el de San Quintín e incluso a los migrantes de las hortalizas que llegan al valle mexicalense. En esta última vertiente, también migran familias enteras.

Los jornaleros indígenas que trabajan en San Quintín, por ejemplo, han logrado establecer redes familiares tan estrechas que les permiten paliar algunas adversidades (Anguiano,1995:61-62).

En la encuesta de 1993-1994 el porcentaje de jornaleros locales con compromisos familiares fue mucho más alto, $60.4 \%$ y $39.6 \%$ de solteros, lo cual nos pudiera indicar que por su permanencia, tienen mayores posibilidades de establecer compromisos y formar una familia.

\footnotetext{
${ }^{26}$ En un trabajo realizado por el autor en 1988 en el valle de Mexicali, se concluyó que $52.5 \%$ de los trabajadores migratorios que llegaban al valle eran analfabetas; mientras que $31.3 \%$ habían cursado cuando menos un año de primaria y sólo $7.5 \%$ habían logrado terminar su instrucción básica. (Moreno, 1988).

Según INRA Delegación Baja California, a nivel nacional $9.8 \%$ de la población mayor de 15 años es analfabeta (véase $L a$ Voz de la Frontera, 9 de septiembre de 1995).
} 


\section{CONDICIONES LABORALES DE LOS TRABAJADORES AGRÍCOLAS EN EL VALLE DE MEXICALI}

\section{Contratación de la mano de obra}

En décadas pasadas el reclutamiento de la mano de obra se venía desarrollando bajo sistemas de "enganche", esto es, se transportaba a la fuerza de trabajo desde su lugar de origen para garantizar su puntual asistencia, por intermedio de un agente contratista enviado por los productores. Sin embargo, en la actualidad las modalidades se han venido diversificando de tal forma que en algunas regiones agrícolas todavía se continúa ejerciendo esa práctica, mientras que en otras ya no.

En el caso específico del valle de Mexicali, la mayoría de los jornaleros agrícolas acuden a ofertar su fuerza de trabajo directamente, y son contratados de manera verbal e individual.

Por lo regular, entre el trabajador y el contratista (que puede ser el propio productor, el capataz o algún familiar), no media ningún contrato escrito. Los pizcadores migrantes del algodón, por ejemplo, en su totalidad manifestaron haber sido contratados de manera individual y en forma verbal en las zonas de mayor concentración como el poblado Kilómetro $57 ; ;^{28}$ por su parte los trabajadores migrantes de las hortalizas se contratan directamente en los campos de cultivo de igual manera que los jornaleros locales.

La contratación verbal trae ciertas desventajas a los trabajadores, puesto que los patrones se sustraen con facilidad a la regulación por parte de las autoridades laborales. La gran mayoría son contratados por el rendimiento a destajo, es decir, por los kilogramos, docenas o piezas que logren realizar. Este sistema trae ciertas ventajas para los productores, pues aumentan la productividad al acelerar el ritmo de trabajo y prolongar la duración del mismo, sin tener que retribuir horas extras. Por lo regular, el propio trabajador prefiere el salario a destajo, porque piensa que mientras más trabaja más gana y así sus ingresos son superiores. Sin embargo, la realidad es otra.

El salario base por lo general es calculado a partir del salario mínimo vigente en la región, modificándolo por la oferta y la demanda de mano de obra y la oscilación de los precios de los productos agrícolas, producto de la demanda en los mercados. En el caso de los productos perecederos

\footnotetext{
${ }^{28}$ Los patrones o sus enviados (que pueden ser sus propios hijos o empleados) llegan por las mañanas a contratarlos, el procedimiento es muy sencillo, únicamente informan cual es el pago, el lugar y cuantos trabajadores ocupan. Los trabajadores que aceptan las condiciones se suben a los camiones y entonces son trasladados a las zonas de cultivo.
} 
(hortalizas) las variaciones son muy frecuentes y alcanzan mejores remuneraciones cuando la cosecha está en su máximo nivel.

El salario base y el rendimiento medio de un trabajador es fijado regularmente por los propios empleadores, los cuales disponen de libertad para manipular la duración del trabajo y la remuneración. ${ }^{29}$

El rendimiento medio calculado por los productores casi nunca corresponde con la realidad, puesto que por lo regular, el parámetro es obtenido del rendimiento de un trabajador experimentado. No se toman en cuenta tampoco otros factores como, el sexo, la edad, las características de la cosecha, las distancias para depositar el producto, etcétera.

Un aspecto que es importante señalar es el relativo a que los trabajadores aportan sus propios instrumentos de labor. En el caso específico de los algodoneros, éstos se ven obligados a traer su propio saco de lona, puesto que es un requisito para inciar el trabajo. En cuanto a los jornaleros locales que trabajan en el corte del cebollín, esparrago y lechuga, también aportan sus instrumentos de trabajo, como cuchillos, tijeras, entre otros.

En cuanto a la seguridad en el empleo, no existe para este tipo de trabajadores, ellos se contratan diariamente (aunque se les pague el fin de semana) y a veces con diferentes patrones. Se encuentran siempre expuestos al trabajo eventual $\mathrm{y}$ al desempleo.

\section{Salario y prestaciones sociales}

La remuneración de los trabajadores agrícolas suele ser por día, a destajo opor tarea, dificilmente por contrato, aunque esto depende del tipo de labor que se desarrolle.

El salario mínimo para el periodo en que se levantó la encuesta de los jornaleros migrantes del algodón (1991) era 10,800 viejos pesos por día y el mayor porcentaje $(68 \%)$ de ingresos de los encuestados se situó entre 1 (3.5 dolares) y menos de 2 salarios mínimos ( 7 dolares). 13\% manifesto obtener menos del mínimo establecido. El promedio general fue de 4.2 dólares por jornada según la paridad de ese tiempo. ${ }^{30}$

En la encuesta de 1994 para los jornaleros locales de las hortalizas, el ingreso se calculo por mes y fue agrupado en rangos que van de 100 a 1,000 nuevos pesos, con intervalos de 300 , el porcentaje mayor ( $54.6 \%$ ) se ubico en uno a menos de dos salarios mínimos, es decir, entre 427.10 nuevos

\footnotetext{
29 Por ejemplo, en el caso del algodón, se toma como rendimiento medio 100 kilogramos, lo cual es equivalente a un salario minímo. Aunque claro, esto se ve modificado cuando se desarrolla la segunda "pasada" en un campo previamente cosechado.

${ }^{30}$ La paridad del peso frente al dólar era de $3,076.5$ viejos pesos por dólar.
} 
pesos y 959.19 nuevos pesos por mes. En este caso alcanzo entre 4.5 y 10 dólares por jornada. Un porcentaje importante, $36.4 \%$ no llegaron al mínimo establecido.

Las pocas diferencias salariales que presentan los dos grupos de trabajadores tienen que ver con el tipo de cultivo en el que laboran y su situacion de residencia. Los migrantes que cosechan el algodon tienen muy pocas posibilidades de influir en la determinación del salario. Por lo regular, con lo que obtienen por día no les alcanza para reproducir su fuerza de trabajo. Los trabajadores locales, por su parte, se insertan en el cultivo de las hortalizas de exportación, que son mucho mejor pagadas.

En el pago a los peones del campo, en general, no se contempla el tiempo de traslado diario a las explotaciones agricolas, que a veces supone trayectos largos. Tampoco se pagan los periodos de inactividad involuntaria, como los lapsos de espera impuestos por el clima, la transportación de un campo de cultivo a otro, la hora de comida, etcétera.

En cuanto a las prestaciones sociales que por ley deberían otorgarse, prácticamente no existen para los jornaleros agrícolas migrantes del algodón, ni de las hortalizas. Algunas excepciones se presentan con los trabajadores locales, sobre todo, aquellos que ya tienen varios años laborando con una misma empresa (ver cuadro 3 ).

En la actividad hortícola, por lo regular los trabajadores laboran seis días a la semana sin percepción del salario dominical. Cuando trabajan todos los días de la semana, no se les paga el doble por el séptimo día, ni se les abona la prima adicional de $25 \%$ del salario por el trabajo efectuado el domingo. Los días no laborados por descanso, enfermedad o por las condiciones climáticas, se consideran simplemente perdidos.

CUADRO 3. Prestaciones sociales entre jornaleros agrícolas migrantes de las hortalizas y jornaleros locales.

\begin{tabular}{lcccc}
\hline Tipo de prestaciones & \multicolumn{2}{c}{ Jornaleros migrantes } & \multicolumn{2}{c}{ Jormaleros locales } \\
Diferentes al & $\begin{array}{c}\text { Sí cuenta } \\
\%\end{array}$ & $\begin{array}{c}\text { No cuenta } \\
\%\end{array}$ & $\begin{array}{c}\text { Sí cuenta } \\
\%\end{array}$ & $\begin{array}{c}\text { No cuenta } \\
\%\end{array}$ \\
IMSS & $\%$ & 100.0 & 4.1 & 95.9 \\
\hline Aguinaldo & 0.0 & 100.0 & 3.4 & 96.6 \\
Reparto de utilidades & 0.0 & 100.0 & .7 & 99.3 \\
Otras & 0.0 & & &
\end{tabular}

FUENTE: IIS-PRONSAG "Encuesta a jornaleros agrícolas del valle de Mexicali", (1994). 
Los peones del campo tampoco se benefician de los días festivos que la Ley federal del trabajo considera como días de descanso obligatorio. Los derechos estipulados en los artículos, 80, 87 y 117 de la Ley federal del trabajo, que otorgan el derecho a los trabajadores temporales a gozar de una determinada cantidad de días de vacaciones, a una prima vacacional $\mathrm{y}$ al reparto de utilidades, no se cumplen cabalmente. ${ }^{31}$

\section{Empleo, riesgos de trabajo y seguridad social}

Las tareas más pesadas del trabajo agrícola, como por ejemplo cargar las cajas de cebollín, las realizan los varones adultos; sin embargo, las actividades que realizan los niños, no por menos pesadas dejan de ser fatigantes $\mathrm{y}$ arriesgadas.

Es común que los peones que trabajan a destajo, con el objetivo de ganar más dinero, prolongan su jornada de trabajo y lo desarrollan con la mayor rapidez posible, reduciendo al mínimo las pausas no remuneradas. Incluso, algunas familias de jornaleros hortícolas se llevan parte del producto a sus hogares para continuar amarrando cebollin durante la noche. Esta situación los expone más a las lesiones profesionales o de otra indole, porque el cansancio se va acumulando.

Los riesgos de trabajo más comunes para estos jornaleros, aparte de los accidentes en el traslado, suelen ser: las cortaduras con los instrumentos de trabajo, los piquetes de animales ponzoñosos y la frecuente exposición a los plaguicidas que se utilizan en la producción de algodón y hortalizas, los cuales se presume pueden traer efectos inmediatos o a largo plazo en sus organismos. $^{32}$

En zonas agrícolas modernas donde la inserción de la mano de obra femenina e infantil se ha estado volviendo común, se ha comprobado que los niños son los que reciben los mayores impactos de las sustancias químicas que se esparcen en los campos de cultivo. ${ }^{33}$

\footnotetext{
31 En 1985, se comenzó a pagar en un empaque hortícola del valle de Mexicali el aguinaldo de manera formal. Esto fue posible gracias a la presión de militantes del Partido Popular Socialista quienes organizaron un movimiento que fue apoyado por los trabajadores, En esa ocasión, se les dio aguinaldo y algunas utilidades a los trabajadores de esa empresa. Sin embargo, las repercusiones del movimiento no fueron generalizadas al conjunto de las empresas empacadoras, mucho menos a los campos de cultivo.

Desafortunadamente no existen estudios sobre las principales enfermedades producidas por las actividades laborales en el valle de Mexicali, pero en otras regiones se ha detectado que las lesiones más frecuentes de los jornaleros agrícolas son: lesiones de los miembros superiores, de las miembros inferiores y del tórax (por las caídas y cortaduras); las enfermedades pulmonares; las enfermedades gastrointestinales y parasitarias y los traumatismos y envenenamientos. (véase Azuela V.M., cit, en Vanakere, 1988:193).
} 
En el valle de Mexicali todavía no se ha cuantificado ni analizado el impacto de los agroquímicos en la salud infantil, sin embargo, resulta elocuente el alto índice de casos de alergias y leucemias que se presentan en la región. ${ }^{34}$

La nula reglamentación en el uso de plaguicidas ponen en peligro a los trabajadores agrícolas, ya que, sin saber, sus organismos son expuestos a intoxicaciones constantes. ${ }^{35}$ Los trabajadores agrícolas mantienen contacto directo con la producción, lo cual los expone sucesiva o simultáneamente a plaguicidas de distintas clases. Los riesgos aumentan cuando los trabajadores ingieren alimentos o consumen productos que están cosechando, como en el caso de las hortalizas frescas.

Indirectamente también las esposas y familiares del trabajador son expuestas a la contaminación, por medio de la ropa, el agua de los canales, etecétera.

En el valle de Mexicali, durante la década 1980 a 1990 se aplicaron alrededor de 5 millones de litros de plaguicidas solamente en el cultivo algodonero e igual número de fertilizantes. ${ }^{36}$

Subsisten serias limitaciones para extender los servicios de salud y de asistencia a las distintas comunidades rurales del país. Los trabajadores agrícolas son quienes más padecen el acceso diferenciado y desigual a estos servicios.

En el valle de Mexicali, en cuanto a la seguridad social, se tiene que el seguro social existe mediante la modalidad de los "pases médicos", pero esto es poco conocido por la mayoría de los trabajadores, especialmente los migrantes a los que en ningún momento se les notifica que tienen ese

${ }^{33}$ En la región del Valle del Yaqui se han desarrollado importantes hallazgos relacionados con el uso de los plaguicidas, por ejemplo se han detectado sustancias atribuibles a agroquímicos en la sangre de ní̄os que todavia no nacen; por otro lado, el número de leucemias on hijos de madres jornaleras agrícolas es extraordinario, 3 por mes en 1991 (Restrepo, 1992).

34 En el municipio de Mexicali se han venido registrando alrededor de 50 casos de leucemia anualmente en las instituciones de salud; asimismo, la localidad está considerada como un lugar de alta incidencia de alergias. Aunque todavía no se ha determinado en forma contundente que los plaguicidas produzcan estos padecimientos, sí existen estudios que relacionan los químicos con las enfermedades, sobre todo en trabajadores del campo (e.g. Moses, 1992 y Bojorquez, 1994).

33 Se han detectado en las listas de productos recomendados por los técnicos de la SARH para los cultivos del valle de Mexicali, alrededor de 20 plaguicidas que han sido restringidos, cancelada su producción o probibidos por autoridades como La Agencia de Protección al Ambiente (BPA), Codigo FAO y Pesticide Action Networt (PAN), tal es el caso de los organoclorados Endosulfan y Dicofol (Moreno, 1992b).

36 Cálculos realizados con datos del departamento de Sanidád Vegetal de fa Secretaría de Agricultura y Recursos Hidráulicos (SARH), 1980-1990. Se sabe que los cultivos hortícolas consumen gran cantidad de plaguicidas y fungicidas, sin embargo se desconocen las cifras, ya que los productores mantienen un hermetismo en cuanto a los compuestos que utilizan. 


\section{CUADRO 4. Seguro Social para jornaleros agrícolas locales y jornaleros migrantes de las hortalizas.}

\begin{tabular}{lcccc} 
Jornaleros agrícolas & \multicolumn{4}{c}{ Modalidad de Seguro Social } \\
del valle de Mexicali & $\begin{array}{c}\text { Con pases } \\
\%\end{array}$ & $\begin{array}{c}\text { Completo } \\
\%\end{array}$ & $\begin{array}{c}\text { No recibió } \\
\%\end{array}$ & $\begin{array}{c}\text { Total } \\
\%\end{array}$ \\
\hline Locales & 62.2 & 8.5 & 29.3 & 100.0 \\
Migrantes & 36.5 & 3.8 & 59.7 & 100.0
\end{tabular}

FUENTE:IIS-UABC, "Encuesta a trabajadores agrícolas en el valle de Mexicali". Mexicali, B.C. 1994.

derecho ${ }^{37}$. El sistema de pases es violatorio de la Ley fundamental del Seguro Social, porque sólo obliga a los patrones a pagar por un seguro colectivo, que toma como base el número de hectáreas que se van a sembrar y la cantidad de trabajadores que supuestamente van a ser contratados. Lo cual no permite que se cotice en favor del trabajador agrícola en particular, y por ello, a éste se le excluye de todos los derechos que otorga la Ley del Seguro Social.

El criterio que utiliza el Consejo Técnico del IMSs para otorgar los llamados pases es bastante difuso, se basa en los jornales de trabajo estimados con base en la superficie y tipo de cultivos, por ejemplo, para el año de 1992 en el valle de Mexicali y San Luis Río Colorado, Sonora, el número de pases otorgados fue de 3,558, para una superficie de 203,029 hectáreas cultivadas (Longoria, 1991:61-62).

En el caso de la actividad horticola, existen organizaciones patronales como La Unión Agricola Regional de Productores de Hortalizas que agrupa a la mayoría de los agricultores que se dedican a sembrar hortalizas. Esta organización establece convenios con el IMSs para dotar a sus trabajadores de la seguridad médica, bajoel régimen ordinario, peroúnicamente gozan de esa prestación los empacadores, transportadores, los guardias y personal de aseo de las empresas, no así los jornaleros.

Para los trabajadores locales, la situación en cuanto al acceso a la seguridad social tiene un matiz diferente con respecto a los migrantes. Por ejemplo, $62.2 \%$ de los encuestados por el IIS-PRONSJAG, sí contaban con

\footnotetext{
37 Los "pases" únicamente cubren las curaciones y los gastos de hospitalización, mas no los salarios de los días que dure la incapacidad. El sistema de pases se instituyó a partir de la reglamentación que se hizo en 1960, del Seguro de los Trabajadores del campo. En ese reglamento, en sus artículos 18 y 20 se estableció que los trabajadores agrícolas eventuales tendrían derecho a recibir atención médica farmacéutica y hospitalaria, en los casos de enfermedades generales contraídas durante el tiempo que presten su servicio.
} 
seguro social bajo la modalidad de pases médicos; $8.5 \%$ tenía seguro social completo y $29.2 \%$ no contaba con seguro social de ningún tipo. Esto significa que sólo una minoría de jornaleros se beneficiaba realmente de los servicios del IMSs. Lo más frecuente es que los trabajadores del campo tengan que sufragar sus propios gastos médicos.

\section{Vivienda de los trabajadores agrícolas}

Como ya se ha mencionado, los trabajadores migrantes del algodon no tienen donde llegar. En el valle no existen albergues ni campamentos destinados para ellos. Lo anterior obliga a los peones migratorios a vivir a la intemperie en las orillas de los poblados, bajo los árboles, en los parques públicos o bien hacinados en cuartos insalubres carentes de los servicios más indispensables, con sus respectivas consecuencias en la salud y vulnerables a las vejaciones y asaltos.

Por lo regular, existen centros de concentración de jornaleros agrícolas migrantes en los poblados mayores, como Kilómetro 43, Kilómetro 57, Los Algodones, Benito Juárez, etcétera. Sin embargo, en ellos no existen albergues como ocurre en otras regiones agrícolas de la república mexicana.

En los lugares de concentración, los trabajadores sufren frecuentemente del hostigamiento policiaco, sus derechos humanos son violados por la población y las propias autoridades locales, quienes consideran que los migrantes traen problemas a los lugares donde llegan. Por razones culturales y su poca educación formal, se encuentran impedidos para defender sus derechos como seres humanos.

En cuanto a los trabajadores migrantes de las hortalizas, ellos optan por rentar habitaciones en alguna cuartería, que por lo regular cuentan con los servicios de agua entubada colectiva, baño colectivo, electricidad para cada cuarto y letrina colectiva. Obviamente, a precios altos. El poblado Venustiano Carranza o Kilometro 57 es el lugar donde más cuarterías de jomaleros migrantes existen. ${ }^{38}$ Otra opción es habitar casas abandonadas sin ningún servicio.

A los productores de hortalizas tampoco les interesa invertir en obras de infraestructura para albergar trabajadores agrícolas migrantes. EI Programa Nacional de Jornaleros Agrícolas recientemente ha puesto en marcha la construcción de viviendas para trabajadores del campo, sin embargo, su número es tan pequeño que no cubre las múltiples necesidades de vivienda; además no consideran a los trabajadores migrantes en sus planes.

${ }^{38}$ En el estudio del IIS-PRONSJAG de 1993-1994 se detectaron más de 15 cuarterías con estas caracteristicas, 
Colateralmente con el dinamismo hortícola de Ios últimos años, también se han venido consolidando una serie de nuevos asentamientos de asalariados del campo.

Precisamente ahí es donde algunas familias rurales de inmigrantes que abandonaron su tierra, han encontrado las condiciones optimas para establecerse en forma definitiva en el valle de Mexicali, lo cual ha traído la proliferación de asentamientos humanos irregulares en las afueras de los poblados, o bien, en las orillas de los drenes y canales de la red de distribución de agua. A esos lugares se les ha dado en llamar "choriceras", por su configuración física. Las "choriceras" se han constituido en verdaderos reservaciones de mano de obra, desde donde se abastece a la producción agrícola local.

En las viviendas de los trabajadores locales inmigrantes encuestados por el IIS-PRONSJAG, se obtuvo que $70 \%$ contaban con agua entubada mientras que el resto se veían obligados a tomar agua de los canales y drenes cercanos. ${ }^{39} 98 \%$ carecían de drenaje, la gran mayoria recurría a las letrinas construidas rústicamente en las orillas de sus propias casas, lo cual contribuye a la contaminación de los mantos freáticos. $96 \%$ de las viviendas contaban con electricidad. Los materiales con los cuales están contruidas las viviendas eran principalmente de cartón, madera, adobe, baras y materiales de desecho. Los pisos por lo regular son de tierra apisonada.

Las condiciones sanitarias que guardan esas viviendas son altamente deficientes, la basura generada simplemente es colocada en alguna orilla de la vivienda, convirtiéndose en basureros.

Los cuartos sirven a la vez de dormitorios, cocina y comedor. Esta multifuncionalidad y la falta de espacio y de mobiliario adecuado, provocan la apilación de utensilios de cocina y de restos de comida que atraen a insectos, moscas, roedores, etcétera, al interior de la vivienda, poniendo en riesgo la salud de su moradores. De igual manera, el piso apisonado de tierra de los cuartos facilita la proliferación de todo tipo de insectos, que pueden afectar principalmente a los niños.

La falta de un lugar específico para la preparación de los alimentos, obliga a emplear algún rincón del cuarto para instalar sus estufas ofogones; el humo y el hollín que desprende éste perjudican también la salud de sus ocupantes.

En lo que respecta a los jomaleros nativos, por lo general, viven en asentamientos humanos ya regularizados, que bien pueden ser ejidos o

\footnotetext{
${ }^{39}$ Las viviendas que cuentan con agua entubada, no necesariamente tienen acceso al agua potable, puesto que el líquido no recibe ningún tratamiento.
} 
propiedad privada; o también en colonias populares de reciente creación, con acceso a los servicios públicos elementales. En la encuesta de referencia se obtuvo que $80 \%$ de las viviendas de estos asalariados tenían agua entubada, fuera y/o dentro de la vivienda; mientras que en $98 \%$ ya se había introducido la electricidad.

En las viviendas de los trabajadores inmigrantes y nativos es común observar que deambulen libremente animales domésticos tales como gallinas, perros, y uno que otro cerdo. Entre esos animales, la tierra y el lodo, juegan los niños más pequeños.

La vivienda de estos jornaleros es precaria. Lo exiguo del salario familiar y el alto costo de la vida en la región, limitan las posibilidades de los jornaleros para disponer de una vivienda adecuada.

\section{Transportación de la mano de obra}

En el caso de los jomaleros migratorios del algodón, la transportación es muy rudimentaria, los dueños de los campos que se van a cosechar o sus enviados, llegan con sus camiones que se utilizan regularmente para transportar "pacas" de alimento para ganado o algodón y "recogen" la mano de obra que necesitan. En otros casos, los propios jornaleros se las ingenian para llegar a los campos de cultivo y ofrecer su mano de obra.

En cambio, en el cultivo de las hortalizas, la situación es un poco diferente. Los requerimientos de fuerza de trabajo para las cosechas son altos, por lo que los patrones se han preocupado por transportar la mano de obra a fin de que ésta llegue temprano. Algunas compañías hortícolas cuentan con camiones de pasajeros especiales para el transporte de los jomaleros, que bien pueden ser rentados o propios.

Otra forma de transportación de esta categoría de trabajadores, es la referida a los "raiteros" o trabajadores que tienen camionetas, en este caso los propios jornaleros que hacen uso de ese servicio dan su aportación económica, de la misma forma lo hacen también los patrones.

\section{Organización sindical}

La organización sindical de los asalariados del campo a nivel nacional es todavía incipiente y se enfrenta a una serie de dificultades. En el caso de jomaleros agrícolas migrantes, las dificultades se incrementan, sobre todo por las características propias de su trabajo, eventual y por la temporalidad. Las distancias entre una zona de absorción de mano de obra y otra son relativamente grandes, por lo que tienden a la movilización geográfica, constituyéndose así en un desestímulo más de organización sindical. 
En el caso particular del valle de Mexicali, la organización de los jornaleros, tanto locales como migrantes, es sumamente incipiente por no decir que nula. ${ }^{40}$

En lo que respecta a los trabajadores agrícolas locales, un porcentaje sumamente pequeño pertenece a centrales campesinas o sindicatos oficiales, sin embargo los beneficios que reciben son raquíticos. ${ }^{41}$ En otros casos, ni siquiera existe el conocimiento de su pertenencia a alguna organización obrera.

Los trabajadores migrantes están en peor situación, en la encuesta a los pizcadores del algodón de 1991-1992, no se encontró a ninguno que estuviera sindicalizado.

Se conocen algunas regiones del país donde los jornaleros agrícolas, a base de sacrificios y luchas intensas, han logrado organizarse, tal es el caso de Chiapas, Sinaloa y San Quintín, donde no sólo han tenido que enfrentarse a los patrones, sino también al propio Estado. ${ }^{42}$

En esos lugares, la intervención de los sindicatos ha redundado en beneficios para los trabajadores, de tal forma que sus condiciones de salario, vivienda, contratación y salud se han mejorado.

Sin embargo, los sindicatos no tienen la fuerza suficiente para organizar al conjunto de los trabajadores, mucho menos aquéllos que no están integrados al partido que tradicionalmente ha gobernado el país.

40 En la historia de la organización sindical de los trabajadores agrícolas del valle de Mexicali, se advierte que el periodo que va de 1920-1940 fue el más prolífico en cuanto a formación de organizaciones de jornaleros según lo refiere Figueroa (1992). En estas dos décadas existió un sindicalismo independiente e influenciado por las ideas magonistas; en el periodo de 1941 a 1965 cuando el al godón se convirtió en el "oro blanco" había 19 sindicatos registrados; en el último periodo que va de la crisis del algodón hasta la actualidad, solamente se registraron 5 sindicatos, todos pertenecientes a centrales oficiales y sin una membresía real.

En el estudio del ns.PRONSJAG de 1993-1994, se preguntó al trabajador si estaban organizados en algún grupo de cualquier índole, $92.7 \%$ contest 6 negativamente, $2.6 \%$ manifestó pertenecer a grupos de solicitantes de tierras, y un porcentaje que no llega a $1 \%$ aceptó pertenecer a sindicatos de jornaleros agrícolas.

42 En el estado existen varios sindicatos que se autonombran defensores de los intereses de los trabajadores agrícolas, pero solamente uno de ellos tiene realmente base social (CIOAC) y esto es en el valle de San Quintín; mientras que otros como SNTACS, afiliado a la CTM, CNC, y demás centrales obreras oficiales, carecen por completo de membresía. Son organizaciones fantasmas que sólo hacen su aparición en el escenario laboral cuando los patrones se encuentran en problemas.

Aun cuando el sNTACs alega contar con la mayoría de los trabajadores afiliados, tanto en el valle de Mexicali como el de San Quintín, la realidad es que los trabajadores del valle mexicalense ignoran completamente su pertenencia a esas organizaciones.

Aunque supuestamente existe un contrato colectivo firmado por el Sindicado Nacional de Trabajadores Asalariados del Campo, afiliado a la cTM y por Ia Unión Regional de Productores de Hortalizas, los trabajadores desconocen totalmente los convenios. 
$\mathrm{La}$ inexistencia de organismos sindicales que defiendan los intereses de los peones del campo, incide para que las deprimentes condiciones laborales prevalezcan en el valle de Mexicali.

\section{ALGUNAS CONSIDERACIONES FINALES}

La agricultura del valle de Mexicali se ha caracterizado por ser totalmente de riego y eminentemente comercial desde su surgimiento. El capital extranjero siempre ha estado presente en toda la historia productiva del valle (Stamatis, 1992b:45). De igual manera, las relaciones salariales han sido las relaciones de trabajo predominantes. A lo largo de su historia, la condición migratoria ha permeado al mercado de trabajo en el valle mexicalense.

Con el descenso de la superficie sembrada de algodon y la introducción e incremento de cultivos hortícolas, se ba venido presentando un proceso de reorganización del empleo, en principio, un número importante de jomaleros locales quedaron desempleados y comenzaron a combinar sus actividades agrícolas con otras no agrícolas.

Con el auge de las hortalizas, algunos trabajadores de la corriente migratoria tradicional (del algódon) se establecieron en los alrededores de los campos hortícolas convirtiéndose en residentes y obligando a sus compañeros locales a entrar en competencia por el empleo; mientras que otros trabajadores migrantes, provenientes de rutas migratorias diferentes a la tradicional, comenzaron a hacer también acto de presencia. Esta situación, permitió que en pocos años se consolidara un mercado de trabajo, compuesto por mano de obra local y otro que incorpora a mano de obra migrante, en donde el primero tiene una predominancia sobre el segundo.

La situación laboral de los trabajadores agrícolas en general en el valle no han cambiado sustancialmente, sin embargo, sí se presentan diferencias en cuanto a sus condiciones de vida y trabajo, derivadas fundamentalmente de su situación de residencia.

La mayoría de los productores de algodon y de hortalizas que contratan mano de obra migrante continúan con las prácticas tradicionales de pagar menores salarios, no incluir prestaciones, ni preocuparse por la vivienda de los trabajadores; solamente unos cuantos incorporan algunas prestaciones, como el seguro social, aguinaldos y reparto de utilidades, en las actividades agrícolas.

Los empleadores de las hortalizas, sobre todo los que destinan su producción hacia la exportación, han flexibilizado sus procesos productivos incorporando a la mano de obra femenina e infantil, asignándoles 
tareas específicas y acentuando la eventualidad del trabajo agrícola. Todo esto, con el objetivo de abaratar el precio de la fuerza de trabajo y tener a su disposición mano de obra suficiente cuando así lo requiera la producción.

La población jornalera del valle de Mexicali se halla expuesta a temperaturas climáticas extremas, frío en invierno y un fuerte calor en verano, así como a riesgos derivados por la exposición a agroquímicos, el consumo de agua no potable y de las precarias condiciones de habitabilidad, que en conjunto generan un cuadro de alto riesgo para la salud.

Las tendencias observadas en esta última década, además de permitirnos distinguir las diferencias entre unos y otros trabajadores agrícolas, nos dan la posibilidad de elaborar una tipología de la mano de obra en el valle de Mexicali, lo cual favorece al entendimiento de sus problemáticas y al diseño de políticas públicas tendientes a buscar su mejoramiento.

\section{BIBLIOGRAFIA}

ASTORGA Lira, Enrique. 1985. Mercado de trabajo rural en México. La mercancía humana. Ediciones ERA.

AGUIRRE Y BELTRÁN, M. y Hubert Carton de Grammont. 1990. Jornaleros agrícolas de México. Ed. Macehual, México.

ANGUIANO Téllez, Maria Eugenia, 1995. Agricultura y migración en el valle de Mexicali. COL.EF, Tijuana, B.C.

BARRON, Antonieta. 1992. "¿Los niños jornaleros agrícolas, tienen derecho a la educación?", La Jornada, Suplemento del campo. 1 de septiembre.

BOJÓRQUEZ Rangel, Guillermo. 1994. "Efectos geotóxicos de Azinfos Metílico y Oxidemetón Metil: insecticidas de amplio uso en Baja California", tesis de maestría, Facultad de Ciencias, UABC, Ensenada, Baja Califomia.

CONAGUA. 1993. "Proyecto de desarrollo parcelario y de redes pequeñas de riego", Distrito de Riego Número 14, Río Colorado, memoria del módulo de riego número 2, Mexicali.

FIGUEROA Ramírez, Leticia. 1993. "La organización de jornaleros agrícolas en el valle de Mexicali, 1920-1990". Estudios Fronterizos, revista del Instituto de Investigaciones Sociales de la UABC, número 27-28, enero-abril, mayo-agosto de 1992, Mexicali, B.C.

INEGI, 1991. XI censo de población y vivienda, 1990. Resultados definitivos. Tabuladores básicos. 
INEA, Delegación de Baja California.1993. Informe Anual 1993. Mexicali, B.C.

IIS-PRONSJAG. 1994. "Encuesta a jornaleros agrícolas del valle de Mexicali", reporte técnico, IS-UABC.

LADMAN, Jerry, 1975. El desarrollo de la economía regional de Mexicali. Un ejemplo de crecimiento impulsado por la exportación.Tempe Arizona, Universidad Estatal de Arizona.

LONGORIA, Eduardo. 1991. "Situación y perspectivas del trabajador agrícola en el valle de Mexicali". Tesis de licenciatura, Escuela de Ciencias Sociales y Políticas, UABC.

MARRONI de Velázquez, María da Gloria. 1993. "La feminización del trabajo agrícola. Un debate abierto". Revista Trabajo, SEP-UAM Iztapalapa, núm. 9, marzo.

MORENO Mena, José A. 1988. "Características de los trabajadores agrícolas del valle de Mexicali". Escuela de Ciencias Sociales y Políticas, UABC, Tesis de licenciatura, Mexicali, B.C.

- 1992a. "Conformación del mercado laboral rural en el valle de Mexicali y las condiciones laborales de los jornaleros agrícolas", tesis de maestria en Desarrollo Rural, UAM-Xochimilco.

- 1992b. "El uso de agroquímicos en el valle de Mexicali: Una propuesta de periodización histórica". Ponencia presentada en el Primer Foro Nacional sobre Agroquímicos y sus efectos en el Medio Ambiente y la Salud Pública. UABC, UPN, COLEF, XIII Ayuntamiento de Mexicali, Mexicali, B.C., 3, 4 y 5 de junio.

MOSES, Marion. 1992. Cosecha dolorosa. Campesinos y pesticidas. Pesticide Education Center, Estados Unidos.

Museo Regional de la Universidad Autónoma de Baja California (hoy Museo Universitario). 1985. "Las hortalizas y los jornaleros en el valle de Mexicali". Folleto de divulgación interna. UABC.

PARE, Luisa. 1977. El proletariado agricola en México. Siglo XXI, $6 \mathrm{a}$. ed., México, D.F.

Programa Nacional de Solidaridad con Jornaleros Agrícolas. 1992. Presentación general y resultados recientes, México.

PRONSJAG y UNICEF, 1995. "Los niños jornaleros agrícolas de San Quintín".

POSADAS, Florencio. 1985. El proletariado agrícola en el estado de Sinaloa. IIES-UAS, Mazatlan, Sinaloa.

Revista Comunidad Educativa. 1996. núm. 9, enero-febrero, Mexicali, B.C.

RESTREPO, Ivan. 1992. Los plaguicidas en México. Oceano, México. 
RODRIGUEZ, Abelardo L. 1927. Memoria administrativa del gobierno del Distrito Norte de la Baja Califormia 1924-1927. Mexicali, B.C.

SAGAR, Delegación Baja California. 1993. Distrito de Riego núm. 14 del Río Colorado, ciclo 1993.

SÁNCHEZ, Muñohierro, Lourdes, 1992. "El tránsito perpetuo". Acta sociológica. FCPS, UNAM, vol. IV, núm. 4-5, enero-agosto.

STAMATIS Maldonado, Martha. 1989. "Proyecto producción de hortalizas mexicanas para el mercado norteamericano", IIS-UABC.

- 1991. "Inversión extranjera y producción de hortalizas". Tesis de maestría, Universidad Autónoma de Chapingo, México, D.F.

- 1992a. "El impacto de la inversión extranjera en el patrón de cultivos y la fuerza de trabajo agrícola en el valle de Mexicali", SOMEDE, México.

- 1992b. "Los contratos de producción en el noroeste de México; el valle de Mexicali a fines de la década de los ochenta", Revista Estudios Fronterizos, IIS-UABC., núm. 30, enero/abril .

VANAKERE, Martine. 1988. "Situación de los jornaleros agrícolas en México". Investigación Económica, núm. 185, julio-septiembre. 